\title{
P-873 - CHARACTERISTICS AND LIFE STYLES OF THE HOMELESS ADULTS IN THE CITY OF PORTO, PORTUGAL
}

\author{
A.J.Marques, F.Campos, C.Queiros \\ ${ }^{1}$ Laboratório de Reabilitação Psicossocial, Faculdade de Psicologia e de Ciências da Educação da \\ Universidade do Porto e Escola Superior de Tecnologia da Saúde do Instituto Politécnico do Porto, ${ }^{2}$ \\ Associação Nova Aurora na Reabilitação e Reintegração Psicossocial, Porto, Portugal
}

Introduction: The phenomenon of homelessness is steadily increasing in urban centers, including in Porto, Portugal, which is a reality not well characterized yet. Some studies have been conducted on this issue, although few focus on the homelessness lifestyle. However this topic seems to be of great interest to study, since it is known that lifestyle affects health and long term patterns of morbidity and mortality.

Aims: The purpose of this study is to characterize homelessness and their lifestyles, exploring correlations with psychopathological symptomatology.

Methods: 29 homelessness of Porto, Portugal, were inquired by the Brief Psychiatric Rating Scale (BPRS - 18 items) and a lifestyle questionnaire (Valente et al., 2009), adapted from the "Dartmouth Assessment of Lifestyle Inventory" (Ford, 2002) and the "Questionário de Atitudes e Comportamentos de Saúde" (Ribeiro, 2004).

Results: Homelessness profiles are in majority male, single, with Portuguese nationality and with low education level. Most of them have unhealthy behaviors, such as smoking and absence physical exercise. However they care about personal hygiene, and demonstrate good sleeping patterns. In terms of psychopathological symptomatology it were identified anxiety, somatic concern, and depressed mood negatively correlated with diverse lifestyle indicators (e.g. stress, sleep hygiene, nutrition, insight, and socialization).

Conclusions: These results reveal that Porto's homelessness profile is similar to general homelessness profiles described by recent international studies. It was also possible to conclude that homelessness lifestyles are characterisd by risky behaviours as well as by psychopathological symptomatology, which seems to be directly correlated. 